\title{
Glucosamine synthetase activity of the colonic mucosa in membranous colitis
}

\author{
M. J. GOODMAN, ${ }^{1}$ P. W. KENT, ${ }^{2}$ AND S. C. TRUELOVE \\ From the Nuffield Department of Clinical Medicine, Radcliffe Infirmary, Oxford
}

SUMMARY Glucosamine synthetase, the first enzyme in glycoprotein synthesis, has been measured in serial rectal biopsies in four patients with membranous colitis. In two of the patients the levels of the enzyme were very high initially and in the other two patients the enzyme levels rose to a peak above the normal range after a delay of up to 10 days. These high levels may be related to the mucus hypersecretion which is a feature of membranous colitis but it seems more likely that they represent the healing of the mucosa.

Membranous (or pseudomembranous) colitis occurs most often after the use of broad-spectrum antibiotics, especially lincomycin and clindamycin (Leading article, 1974), but it is also seen in patients who have not been taking antibiotics (Penner and Bernheim, 1939). The inflamed colonic mucosa is covered by an adherent membrane of fibrin, mucus, and inflammatory cells (Goulston and McGovern, $1965)$ and the glands are frequently dilated with mucus. Glucosamine synthetase, the enzyme which catalyses the synthesis of glucosamine-6-phosphate from fructose-6-phosphate and glutamine, is the first step, and probably a rate-limiting step, in the biosynthesis of glycoproteins, including gastrointestinal mucus (Lukie and Forstner, 1972). A method has been developed for the assay of this enzyme, requiring only $4 \mathrm{mg}$ tissue as can be provided by one-half of a rectal biopsy obtained through a sigmoidoscope (Goodman et al., 1977). This assay has been used to measure the glucosamine synthetase activity in the rectal biopsies of four patients with membranous colitis.

\section{Methods}

Glucosamine synthetase was measured by the method of Goodman et al. (1977) in serial rectal biopsies of four patients presenting with membranous colitis. The clinical details of the four

${ }^{1}$ Present address: Department of Medicine, University of Chicago, USA.

${ }^{2}$ Present address: Director, Glycoprotein Research Unit, University of Durham.

Received for publication 12 August 1976
Table Clinical details of four patients with membranous colitis whose rectal biopsies were assayed for glucosamine synthetase

\begin{tabular}{llllll}
\hline Patient & $\begin{array}{c}\text { Age } \\
(y r)\end{array}$ & Sex & $\begin{array}{l}\text { Preceding } \\
\text { antibiotics }\end{array}$ & $\begin{array}{l}\text { Diarrhoea } \\
\text { with mucus }\end{array}$ & $\begin{array}{l}\text { Typical } \\
\text { pseudo- } \\
\text { membrane on } \\
\text { histology }\end{array}$ \\
\hline Q.S. & 58 & M & - & + & + \\
J.R. & 68 & M & Seven antibiotics & + & + \\
M.T. & 67 & F & Cloxacillin & + & + \\
E.B. & 68 & F & Clindamycin & + & + \\
\hline
\end{tabular}

patients are shown in the Table. Three of the patients had received antibiotics, although one patient had not. All four patients complained of excessive amounts of mucus in their stools.

A rectal biopsy was taken and assayed for glucosamine synthetase at the time of diagnosis of membranous colitis. Each patient was then treated with a five-day intravenous regime, the patients receiving $40-60 \mathrm{mg}$ prednisolone-21-phosphate daily (Goodman and Truelove, 1976). A second rectal biopsy was taken and assayed for the enzyme on the fifth day, after which the patient was treated with oral prednisolone and prednisolone retention enemas for a further six weeks. A third biopsy was taken on the 10th day and further biopsies were taken at six weeks in three of the patients, at three months in two of the patients, and at three weeks in one patient who was lost to further follow-up.

Although membranous colitis can be fatal, all these patients showed complete clinical and sigmoidoscopic recovery. 

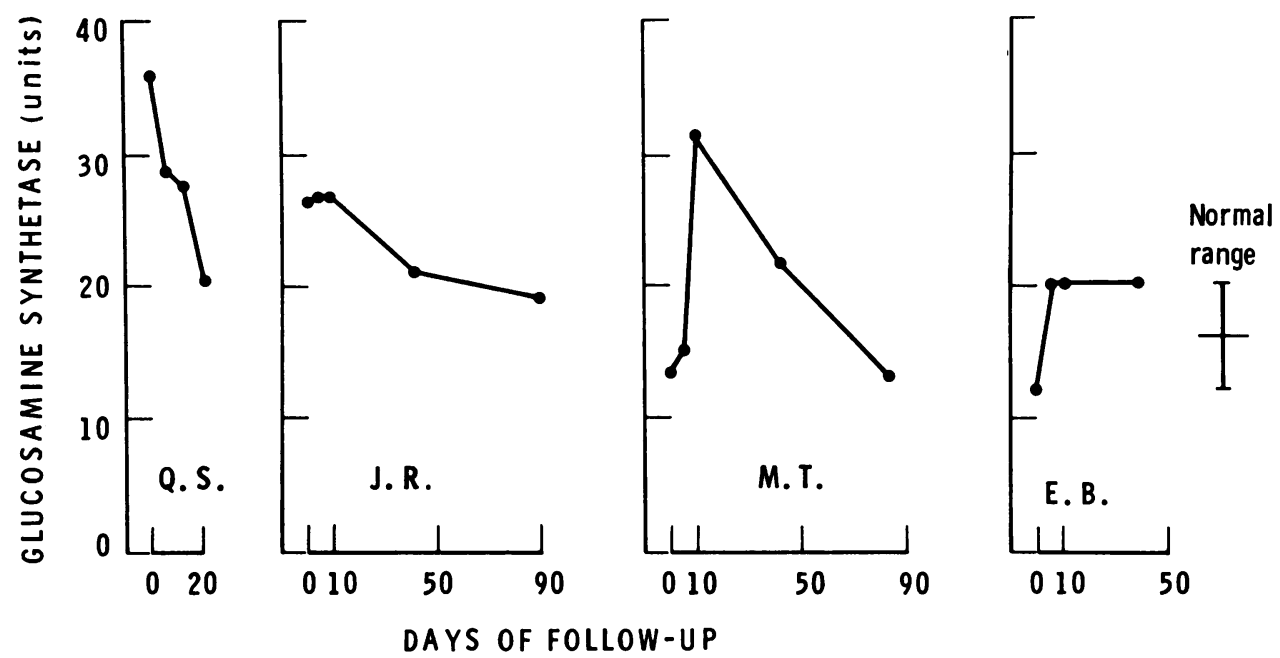

Figure Glucosamine synthetase levels in serial rectal biopsies of four patients with membranous colitis. After the first biopsy, all the patients were treated with prednisolone for six weeks. (The mean $\pm 1 S D$ for a control series of normal colonic mucosa is also shown.)

\section{Results}

The glucosamine synthetase levels (in $\mu$ mol glucosamine synthesised/h/g wet wt) in the serial rectal biopsies of the four patients are shown in the Figure. The normal range for the enzyme in the human colonic mucosa, as determined in rectal biopsies of patients with the irritable colon syndrome and in the histologically normal cut ends of colectomy specimens for carcinoma of the colon and localised diverticulitis, is 13.77 units \pm 3.97 units (SD) (Goodman et al., 1977). All four patients with membranous colitis started at a peak or rose to a peak of 20.0 units or more. The peak levels attained were $36 \cdot 0,27 \cdot 0,31 \cdot 7$, and $20 \cdot 5$ units respectively, in all cases the peak being at the time of diagnosis or within 10 days of the beginning of treatment. The first three patients showed a fall in enzyme levels after the peak.

\section{Discussion}

In membranous colitis, the glucosamine synthetase activity of the rectal mucosa appears to rise to high levels, of up to $36.0 \mu \mathrm{mol}$ glucosamine synthesised $/ \mathrm{h} / \mathrm{g}$ wet wt, which were similar to those recorded in two samples of colonic mucosa in patients with ulcerative colitis with hypertrophic crypts (which were 31.6 and $26 \cdot 8$ units respectively) (Goodman et al., 1977). In fact, the glucosamine synthetase levels at the peak in two of the patients with membranous colitis were higher than all of those measured by us in 138 rectal biopsies taken from 71 patients with ulcerative colitis (Goodman et al., 1977).

The glycoproteins synthesised in the intestinal mucosa include the secreted mucus, which is the main component (Forstner, 1970; Forstner et al., 1973), and the immunoglobulins. It is unlikely that the high levels of glucosamine synthetase which we have found in membranous colitis are related to mucus hypersecretion, because in two of the patients the levels were below 15.0 units in the first biopsy at a time when the symptom of mucus excretion was most severe and when the biopsy showed the most typical features of membranous colitis. In the patient (M.T.) who reached a peak of 31.7 units on the 10 th day, the level was still below 17.0 units on the fifth day (Figure). In none of the biopsies was there any diminution of the epithelial cell density on histology.

The peak effect in the glucosamine synthetase levels does not seem to be related to steroid therapy. Two of the patients, both with very high peaks, were at their peak levels before treatment with prednisolone was started. The peak effect is most probably due to the healing of the mucosa and probably represents epithelial cell regeneration. Our previous paper showed similar peak effects in the glucosamine synthetase activity of rectal biopsies in patients in an acute attack of ulcerative colitis who subseqentuly recovered from their attack, although not in patients who did not recover (Goodman et al., 1977). In neonatal rat liver, partial hepatectomy induces a rise in the glucosamine synthetase activity of the regenerating liver (Akamatsu and Maeda, 
1971). The peak may be higher in membranous colitis than in ulcerative colitis because, once the damaging agent has been withdrawn, the bowel in membranous colitis is probably fundamentally normal and capable of a vigorous recovery.

M.J.G. acknowledges the generous support of the Wellcome Trust and P.W.K. that of the Cystic Fibrosis Research Foundation.

\section{References}

Akamatsu, N., and Maeda, H. R. (1971). Formation of glucosamine 6-phosphate in regenerating rat liver. Biochimica et Biophysica Acta, 244, 311-317.

Forstner, G. (1970). $\left[1-^{14} \mathrm{C}\right]$ Glucosamine incorporation by subcellular fractions of small intestinal mucosa. Journal of Biological Chemistry, 245, 3584-3592.
Forstner, J., Taichman, N., Kalnins, V., and Forstner, G. (1973). Intestinal goblet cell mucus: isolation and identification by immunofluorescence of a goblet cell glycoprotein. Journal of Cell Science, 12, 585-602.

Goodman, M. J., Kent, P. W., and Truelove, S. C. (1977). The glucosamine synthetase activity of the colonic mucosa in ulcerative colitis and Crohn's disease. Gut, 18, 219-228.

Goodman, M. J., and Truelove, S. C. (1976). Intensive intravenous regimen for membranous colitis. British Medical Journal 2, 354.

Goulston, S. J. M., and McGovern, V. J. (1965). Pseudomembranous colitis. Gut, 6, 207-212.

Leading article (1974). Lincomycin and clindamycin colitis. British Medical Journal, 4, 65-66.

Lukie, B. E., and Forstner, G. G. (1972). Synthesis of intestinal glycoprotein. Incorporation of $\left[1-{ }^{14} \mathrm{C}\right]$-glucosamine in vitro. Biochimica et Biophysica Acta, 261, 353-364.

Penner, A., and Bernheim, A. I. (1939). Acute postoperative enterocolitis. A study on the pathologic nature of shock. Archives of Pathology, 27, 966-983. 